\title{
Using a fingertip whole blood sample for rapid fatty acid measurement: method validation and correlation with erythrocyte polar lipid compositions in UK subjects
}

\author{
J. Gordon Bell ${ }^{1 *}$, Elizabeth E. Mackinlay ${ }^{1}$, James R. Dick ${ }^{1}$, Irene Younger $^{1}$, Bill Lands ${ }^{2}$ \\ and Thomas Gilhooly ${ }^{3}$ \\ ${ }^{1}$ Institute of Aquaculture, University of Stirling, Stirling FK9 4LA, Scotland, UK \\ ${ }^{2}$ Department of Biochemistry, College of Medicine, University of Illinois at Chicago, 1853 West Polk Street, A312, M/C 536, \\ Chicago, IL 60612, USA \\ ${ }^{3}$ Glasgow Health Solutions Limited, Omega House, 12 Sovereign Court, Wyrefields, Poulton Le Fylde, Lancashire FY6 8JX, UK
}

(Received 7 January 2011 - Revised 17 March 2011 - Accepted 17 March 2011 - First published online 1 June 2011)

\section{Abstract}

It is well accepted that $n$-3 long-chain PUFA intake is positively associated with a range of health benefits. However, while benefits have been clearly shown, especially for CVD, the mechanisms for prevention/benefit are less understood. Analysis of plasma and erythrocyte phospholipids (PL) have been used to measure the status of the highly unsaturated fatty acids (HUFA), especially EPA $(20: 5 n-3)$ and DHA $(22: 6 n-3)$, although the time and complexity of the process places limitations on the sample numbers analysed. An assay has been developed using whole blood, collected by finger prick, and stored on absorbant paper, subjected to direct methylation and fatty acids quantified by automated GC. Tests on fatty acid stability show that blood samples are stable when stored at $-20^{\circ} \mathrm{C}$ for 1 month although some loss of HUFA was seen at $4^{\circ} \mathrm{C}$. A total of fifty-one patients, including twenty-seven who consumed no fatty acid supplements, provided a blood sample for analysis. Concentrations of all major fatty acids were measured in erythrocyte PL and whole blood. The major HUFA, including EPA, DHA and arachidonic acid (ARA; 20:4n-6), as well as the ARA:EPA ratio and the percentage $n-3$ HUFA/total HUFA all showed good correlations, between erythrocyte PL and whole blood. Values of $r^{2}$ ranged from 0.48 for ARA to 0.95 for the percentage of $n$-3 HUFA/total HUFA. This assay provides a non-invasive, rapid and reliable method of HUFA quantification with the percentage of $n-3$ HUFA value providing a potential blood biomarker for large-scale nutritional trials.

Key words: Blood fatty acids: Rapid analysis: Long-chain PUFA: Percentage of $n$-3 HUFA/total HUFA

The importance of diet and its relationship to human health was recognised by Hippocrates who stated 'Leave your drugs in the chemist's pot if you can heal the patient with food' and this view is now well respected in many branches of nutritional and clinical science. In the last 100 years we have seen a rapid rise in conditions with an inflammatory pathology including CVD, immune dysfunction, rheumatoid arthritis and bowel inflammation, among others ${ }^{(1-4)}$.

In the 1970s, studies on Greenland Inuit populations established that, despite high lipid intake, cardiac and other inflammatory illnesses were virtually absent in these populations and that the protective effect was linked to high fish intake $^{(5)}$. Nowadays, the health benefits of consuming marine products, rich in $n-3$ highly unsaturated fatty acids
(HUFA), most notably EPA (20:5n-3) and DHA (22:6n-3), are well recognised. In addition to their efficacy in treating the inflammatory conditions described above, there is also considerable evidence of $n-3$ HUFA benefits for a range of neural and behavioural disorders as well as for maternal and child health $^{(6-8)}$.

The classical methods of blood fatty acid analysis have used a range of blood fractions including erythrocytes and plasma polar and total lipid (TL) fatty acids as well as whole blood $^{(9,10)}$. The drawbacks of collecting venous blood from the antecubital vein are the time and costs involved and these methods are not always applicable for young or vulnerable patients or for individuals that require blood collection on a frequent basis. Whole blood is usually taken

Abbreviations: ARA, arachidonic acid; BHT, butylated hydroxytoluene; FAME, fatty acid methyl esters; HUFA, highly unsaturated fatty acids; PL, phospholipids; TL, total lipids.

*Corresponding author: Professor J. G. Bell, fax +44 1786 472133, email g.j.bell@stir.ac.uk 
by venepuncture, erythrocytes separated by centrifugation, lipids extracted by organic solvents, the polar lipid fraction isolated, methylated and purified to produce fatty acid methyl esters (FAME) before measuring the fatty acids by GLC. This process can take $4-5 \mathrm{~d}$ from sample delivery to reporting the FAME data.

Initial attempts to develop rapid analysis methods include an early study by Lands et $a l^{(11)}$, using plasma that was directly methylated without extraction but this was not widely adopted. By comparison, measuring whole blood fatty acids, collected by means of a fingertip lance, allows collection of high sample numbers that can be subjected to high-throughput automated procedures that allow results to be delivered in a few days at an economical price. A relatively small number of studies have investigated the use of fingertip whole blood to quantify fatty acid compositions to date ${ }^{(12-16)}$. There is currently a need for an economical, rapid, minimally invasive, accurate and validated system to measure HUFA proportions that reflect and monitor an individual's dietary intake of essential fatty acids, which provides a valid health risk assessment for individual patients. Such assessments, based on the methodologies described in the present study, should be of benefit when screening larger population groups and could be utilised in both public health initiatives as well as in clinical practice.

The aims of the present study were to validate a simple and rapid method of blood collection using a fingertip whole blood sample and compare the fatty acid compositions obtained with erythrocyte polar lipid fatty acid compositions. Samples were collected from patients having variable $n-3$ HUFA intakes ranging from those consuming low-fish diets with no fish oil supplements to those consuming both fish and supplements. Fingertip samples were analysed following a direct methylation technique and compared with the erythrocytes that were extracted, the polar lipid fraction isolated and methylated by standard wet chemistry methods and analysed by conventional GC procedures.

\section{Materials and methods}

\section{Study participants}

A total of fifty-one patients attending the Essential Health Clinic, Rutherglen, Glasgow provided samples between May and July 2009. In the total sample of fifty-one patients, twenty-six had not taken any fish oil supplements in the preceding 3 months and this group was used as a fish oil-naïve control population.

\section{Blood collection}

Whole blood was collected using a blood lance (Accu-Chek ${ }^{\circledR}$, Safe-T-Pro Plus, Roche Diagnostics GmbH, Mannheim, Germany). An additional 2-4 $\mathrm{ml}$ of whole blood was collected from each patient, to provide additional blood should a re-test be required, which was stored in glass tubes containing EDTA as an anticoagulant and sent to the Nutrition Group Laboratories at the University of Stirling, along with the blood spot cards, by next day delivery. The present study was conducted according to the guidelines laid down in the Declaration of Helsinki. Verbal informed consent was obtained from all patients and verbal consent was witnessed and formally recorded.

\section{Fatty acid stability test}

Blood samples were obtained from four patients and the samples were pooled and thoroughly mixed. We prepared twenty-two Whatman 903 cards by adding butylated hydroxytoluene (BHT; $50 \mathrm{mg} / 100 \mathrm{ml}$ in ethanol) to fully cover each collection spot. The cards were air-dried for $1 \mathrm{~h}$ and placed in a sealed polythene bag overnight. The following day the blood sample was mixed and $50 \mu \mathrm{l}$ was applied to each of eighty-eight spots. The blood sample was mixed after every twelve spots. We placed forty-four blood spots in either a fridge at $4{ }^{\circ} \mathrm{C}$ or a freezer at $-20^{\circ} \mathrm{C}$. The samples were analysed at time 0 ( $3 \mathrm{~h}$ after spotting) and subsequent samples were removed for analysis after, $48 \mathrm{~h}, 7,14$, and $28 \mathrm{~d}$ in storage. The data for arachidonic acid (ARA), EPA, DHA, ARA:EPA ratio and percentage $n$-3

Table 1. Stability of blood spot fatty acid compositions (percentage of total fatty acids) stored at 4 and $-20^{\circ} \mathrm{C}$ for $28 \mathrm{~d}$

(Mean values and standard deviations, $n 3$ )

\begin{tabular}{|c|c|c|c|c|c|c|c|c|c|c|c|}
\hline \multirow[b]{2}{*}{ Fatty acid/time } & \multicolumn{2}{|c|}{ 3h Post-drying } & \multicolumn{2}{|c|}{$48 \mathrm{~h}$} & \multicolumn{2}{|c|}{$7 d$} & \multicolumn{2}{|c|}{$14 d$} & \multicolumn{2}{|c|}{$28 d$} & \multirow{2}{*}{$\begin{array}{l}\% \text { Reduction/ } \\
\text { increase }\end{array}$} \\
\hline & Mean & SD & Mean & SD & Mean & SD & Mean & SD & Mean & SD & \\
\hline \multicolumn{12}{|l|}{$4^{\circ} \mathrm{C}$} \\
\hline $20: 4 n-6$ & $10 \cdot 05^{\mathrm{a}}$ & 0.06 & $9 \cdot 66^{\mathrm{b}}$ & 0.07 & $9 \cdot 69^{b}$ & 0.05 & $9 \cdot 47^{\mathrm{c}}$ & 0.06 & $8.59^{d}$ & 0.07 & 14.5 \\
\hline $20: 5 n-3$ & $2 \cdot 32^{\mathrm{a}}$ & 0.05 & $2 \cdot 01^{\mathrm{b}}$ & 0.07 & $1.98^{b}$ & 0.05 & $1.92^{b}$ & 0.02 & $1.66^{\mathrm{c}}$ & 0.08 & 28.5 \\
\hline $22: 6 n-3$ & $5 \cdot 10^{\mathrm{a}}$ & 0.02 & $4.91^{\mathrm{b}}$ & 0.03 & $4 \cdot 84^{b, c}$ & 0.06 & $4 \cdot 58^{d}$ & 0.07 & $3.81^{\mathrm{e}}$ & 0.02 & $25 \cdot 3$ \\
\hline ARA/EPA & $4 \cdot 33^{\mathrm{c}}$ & 0.08 & $4 \cdot 61^{b, c}$ & 0.15 & $4.89^{\mathrm{a}, \mathrm{b}}$ & 0.13 & $4.93^{\mathrm{a}, \mathrm{b}}$ & 0.06 & $5 \cdot 17^{\mathrm{a}}$ & 0.21 & $16 \cdot 3^{\star}$ \\
\hline$\% n-3$ HUFA/total HUFA & $42 \cdot 68^{a}$ & 0.28 & $42 \cdot 46^{\mathrm{a}}$ & 0.26 & $41 \cdot 62^{\mathrm{b}}$ & $0 \cdot 11$ & $41 \cdot 08^{\mathrm{C}}$ & 0.08 & $39 \cdot 27^{d}$ & $0 \cdot 15$ & 8.0 \\
\hline \multicolumn{12}{|l|}{$-20^{\circ} \mathrm{C}$} \\
\hline $20: 4 n-6$ & $10 \cdot 05$ & 0.06 & 9.99 & 0.06 & $10 \cdot 12$ & 0.04 & $10 \cdot 11$ & 0.15 & 9.92 & 0.09 & 0 \\
\hline $20: 5 n-3$ & $2 \cdot 32^{\mathrm{a}}$ & 0.05 & $2 \cdot 23^{\mathrm{a}}$ & 0.01 & $2 \cdot 23^{\mathrm{a}}$ & 0.04 & $2 \cdot 11^{\mathrm{b}}$ & 0.02 & $2 \cdot 12^{\mathrm{b}}$ & 0.05 & $9 \cdot 1$ \\
\hline $22: 6 n-3$ & $5 \cdot 10^{\mathrm{a}}$ & 0.02 & $5 \cdot 15^{\mathrm{a}}$ & 0.03 & $5 \cdot 22^{\mathrm{a}}$ & 0.05 & $5 \cdot 12^{\mathrm{a}, \mathrm{c}}$ & 0.09 & $4 \cdot 86^{\mathrm{b}, \mathrm{c}}$ & 0.08 & 4.7 \\
\hline ARA/EPA & $4 \cdot 33^{\mathrm{c}}$ & 0.08 & $4 \cdot 48^{\mathrm{b}, \mathrm{c}}$ & 0.04 & $4.57^{a, b}$ & 0.02 & $4 \cdot 74^{\mathrm{a}}$ & 0.08 & $4 \cdot 66^{\mathrm{a}}$ & 0.11 & $8 \cdot 7^{\star}$ \\
\hline$\% n-3$ HUFA/total HUFA & $42 \cdot 68^{\mathrm{a}}$ & 0.28 & $42 \cdot 77^{\mathrm{a}}$ & 0.04 & $42 \cdot 66^{a}$ & 0.15 & $41 \cdot 66^{b}$ & 0.08 & $41.41^{b}$ & 0.38 & 3.0 \\
\hline
\end{tabular}

a,b,c,d Mean values with unlike superscript letters were significantly different $(P<0.05)$.

${ }^{*}$ Increase. 
HUFA/total HUFA are shown in Table 1. A second test was conducted to determine whether pre-treating the Whatman collection cards with two drops of BHT in ethanol $(50 \mathrm{mg}$ / $100 \mathrm{ml}$ ethanol), prior to adding the blood sample, reduced fatty acid losses compared to cards with no addition of BHT. A single blood sample was mixed and spotted onto Whatman collector cards after the BHT solution was fully dry and the same blood sample was added to cards with no BHT. An initial sample was analysed for fatty acid compositions $3 \mathrm{~h}$ after blood addition and again after 1-4 weeks storage in Zip-Lock foil bags with desiccant at room temperature.

\section{Lipid extraction, preparation of phospholipid fraction and preparation of fatty acid methyl esters in erythrocytes and whole blood}

The lipid extraction of erythrocytes was a modification of the method of Bligh \& Dyer ${ }^{(17)}$. The erythrocyte pellet was thawed and $0 \cdot 25-0.50 \mathrm{ml}$ placed in a $15 \mathrm{ml}$ stoppered tube. Methanol $(5 \mathrm{ml})-0.01 \%$ BHT $(\mathrm{w} / \mathrm{v})$ was added and then mixed on a vortex mixer. After $20 \mathrm{~min}$ at room temperature $2.5 \mathrm{ml}$ of chloroform-BHT was added, mixed and left at room temperature for a further $40 \mathrm{~min}$. The tubes were centrifuged at $500 \mathrm{~g}$ for $5 \mathrm{~min}$ and the supernatant decanted into a clean $15 \mathrm{ml}$ tube after filtering though Whatman No. 1 paper. A further $2.5 \mathrm{ml}$ of chloroform-BHT and $2.5 \mathrm{ml}$ of $0.88 \%$ $\mathrm{KCl}(\mathrm{w} / \mathrm{v})$ were added, mixed and centrifuged as above. The lower chloroform layer was removed and filtered into a $15 \mathrm{ml}$ tube and evaporated under $\mathrm{N}_{2}$. The lipid was taken up in $0.8 \mathrm{ml}$ of chloroform-methanol $(2: 1, \mathrm{v} / \mathrm{v})$ and placed in a weighed glass vial. This was dried under $\mathrm{N}_{2}$ and desiccated for $16 \mathrm{~h}$. After recording the lipid weight the sample was re-suspended in chloroform-methanol $(2: 1, \mathrm{v} / \mathrm{v})+\mathrm{BHT}$, at a concentration of $10 \mathrm{mg} / \mathrm{ml}$ and stored at $-70^{\circ} \mathrm{C}$ until analysed.

A PL fraction was prepared from $0.5 \mathrm{mg}$ of TL applied to a $20 \times 20 \mathrm{~cm}$ silica gel 60 TLC plate (VWR, Lutterworth, Leicestershire, UK) and developed in isohexane-diethyl ether-acetic acid (80:20:1, by vol.) and dried for a few minutes at room temperature. The plate was sprayed lightly with 2,7-dichlorofluoricein $(0 \cdot 1 \%, \mathrm{w} / \mathrm{v})$ in $97 \%$ methanol $(\mathrm{v} / \mathrm{v})$ and the PL bands on the origin scraped from the plate and placed in a $15 \mathrm{ml}$ test-tube. FAME were prepared by acid-catalysed transesterification in $2 \mathrm{ml}$ of $1 \% \mathrm{H}_{2} \mathrm{SO}_{4}$ in methanol at $50^{\circ} \mathrm{C}$ overnight ${ }^{(18)}$. The samples were neutralised with $2.5 \mathrm{ml}$ of $2 \% \mathrm{KHCO}_{3}$ and extracted with $5 \mathrm{ml}$ isohexanediethyl ether $(1: 1, \mathrm{v} / \mathrm{v})+$ BHT. The samples were then re-extracted with $5 \mathrm{ml}$ isohexane-diethyl ether (1:1) and the combined extracts were dried and dissolved in $0.3 \mathrm{ml}$ of isohexane prior to fatty acid analysis.

The dried whole blood sample was detached from the collection device using forceps and placed into a screw-cap vial containing $1 \mathrm{ml}$ of a methylating solution (1.25 M-methanol$\mathrm{HCl}$ ). The vials were placed in a hot block at $70^{\circ} \mathrm{C}$ for $1 \mathrm{~h}$. The vials were allowed to cool to room temperature and then $2 \mathrm{ml}$ of distilled water and $2 \mathrm{ml}$ of saturated $\mathrm{HCl}$ solution were added. FAME were then extracted using $2 \times 2 \mathrm{ml}$ of isohexane.

\section{Measurement of erythrocyte and whole blood fatty acids}

FAME were separated and quantified by GLC (ThermoFisher Trace, Hemel Hempstead, Herts, UK) using a $60 \mathrm{~m} \times$ $0.32 \mathrm{~mm} \times 0.25 \mu \mathrm{m}$ film thickness capillary column (ZB Wax; Phenomenex, Macclesfield, Cheshire, UK). $\mathrm{H}_{2}$ was used as a carrier gas at a flow rate of $4.0 \mathrm{ml} / \mathrm{min}$ and the temperature programme was from 50 to $150^{\circ} \mathrm{C}$ at $40^{\circ} \mathrm{C} / \mathrm{min}$ then to $195^{\circ} \mathrm{C}$ at $2^{\circ} \mathrm{C} / \mathrm{min}$ and finally to $215^{\circ} \mathrm{C}$ at $0.5^{\circ} \mathrm{C} / \mathrm{min}$. Individual FAME were identified compared to well-characterised in-house standards as well as commercial FAME mixtures (Supelco $^{\text {тм }} 37$ FAME mix; Sigma-Aldrich Limited, Gillingham, Dorset, UK). The precision of the whole-blood fatty acid analysis was conducted by measuring triplicate samples over four successive days to provide mean and standard deviation and $\mathrm{CV} \%(n$ 12).

\section{Statistical analysis}

The significance of the differences $(P<0.05)$ between groups was determined by the use of Student's $t$ test or in the case of the storage-losses study one-way ANOVA was used. For the latter, significant differences were tested using Tukey's multiple comparisons test. Regression analysis was used to obtain correlation coefficients from plots of blood fatty acids from different fractions. ANOVA, $t$ tests and regression analyses were performed using the Graphpad Prism ${ }^{\text {TM }}$ (version 4.0) statistical package (Graphpad Software, San Diego, CA, USA).

\section{Results}

The data from the blood stability trial are shown in Table 1. For ARA stored at $-20^{\circ} \mathrm{C}$ for $28 \mathrm{~d}$ there was no change in the percentage values over the $28 \mathrm{~d}$ period. However, when stored at $4^{\circ} \mathrm{C}$ the percentage values were significantly reduced from $3 \mathrm{~h}$ values when sampled after $48 \mathrm{~h}$ and $7 \mathrm{~d}$, and were reduced further following storage for 14 and $28 \mathrm{~d}$ with the reduction between $3 \mathrm{~h}$ and $28 \mathrm{~d}$ being $14.5 \%$. For EPA stored at $-20^{\circ} \mathrm{C}$ there was no reduction up to $7 \mathrm{~d}$ storage but a significant reduction was observed in samples stored for 14 and $28 \mathrm{~d}(9 \cdot 1 \%$ loss at $14 \mathrm{~d})$. For EPA stored at $4{ }^{\circ} \mathrm{C}$ there was an initial loss after $48 \mathrm{~h}$ and further reductions after 14 and $28 \mathrm{~d}$ (28.8\% reduction at $28 \mathrm{~d})$. For DHA stored at $-20^{\circ} \mathrm{C}$ the reductions were similar to EPA at the same temperature with losses at $28 \mathrm{~d}$ being $4.7 \%$. As with EPA at $4^{\circ} \mathrm{C}$ DHA dropped significantly after $48 \mathrm{~h}$ and $7 \mathrm{~d}$ and then again after 14 and $28 \mathrm{~d}$ such that the overall reduction was $25 \cdot 3 \%$. For the ARA:EPA ratio at $-20^{\circ} \mathrm{C}$ the ratio rose after 14 and $28 \mathrm{~d}$ in storage with the increase due to ARA being more stable than EPA and the increase between $3 \mathrm{~h}$ and $14 \mathrm{~d}$ was $8.7 \%$. The ARA:EPA ratio at $4{ }^{\circ} \mathrm{C}$ increased from 4.33 at $3 \mathrm{~h}$ sampling to 5.17 after $28 \mathrm{~d}$ in storage representing a $16.3 \%$ increase in the ARA:EPA ratio over $28 \mathrm{~d}$. The percentage $n$ - 3 HUFA:total HUFA ratio at $-20^{\circ} \mathrm{C}$ was stable up to $7 \mathrm{~d}$ storage and declined significantly after 14 and $28 \mathrm{~d}$ storage. The reduction over $28 \mathrm{~d}$ was only $3 \%$. By comparison, the percentage $n-3$ HUFA:total HUFA ratio stored at $4^{\circ} \mathrm{C}$ showed a significant reduction after 
Table 2. A comparison of the fatty acid compositions (percentage of total fatty acids) of the erythrocyte polar lipid fraction and whole blood fatty acid compositions in patients

(Mean values and standard deviations, $n 51$ )

\begin{tabular}{|c|c|c|c|c|c|}
\hline \multirow[b]{2}{*}{ Fatty acid } & \multicolumn{2}{|c|}{ Erythrocyte PL } & \multicolumn{2}{|c|}{ Whole blood } & \multirow[b]{2}{*}{$P$} \\
\hline & Mean & SD & Mean & SD & \\
\hline $14: 0$ & 0.30 & 0.08 & 0.95 & 0.38 & $<0.0001$ \\
\hline $15: 0$ & 0.18 & 0.03 & 0.46 & 0.20 & $<0.0001$ \\
\hline $16: 0$ & 21.09 & $1 \cdot 10$ & 23.74 & 1.61 & $<0.0001$ \\
\hline $18: 0$ & $15 \cdot 21$ & 0.78 & 11.74 & $1 \cdot 20$ & $<0.0001$ \\
\hline $20: 0$ & 0.29 & 0.04 & 0.21 & 0.04 & $<0.0001$ \\
\hline $22: 0$ & 0.72 & 0.09 & 0.28 & 0.07 & $<0.0001$ \\
\hline $24: 0$ & $2 \cdot 00$ & 0.22 & 0.31 & $0 \cdot 10$ & $<0.0001$ \\
\hline Total SFA & 39.78 & 0.91 & $37 \cdot 70$ & $1 \cdot 76$ & $<0.0001$ \\
\hline $16: 1 n-9$ & 0.09 & 0.03 & 0.72 & 0.40 & $<0.0001$ \\
\hline $16: 1 n-7$ & 0.33 & 0.12 & 1.54 & 0.57 & $<0.0001$ \\
\hline $18: 1 n-9$ & $12 \cdot 78$ & 1.02 & $20 \cdot 32$ & 2.49 & $<0.0001$ \\
\hline $18: 1 n-7$ & 1.42 & 0.16 & 1.93 & 0.26 & $<0.0001$ \\
\hline $20: 1 n-9$ & 0.24 & 0.06 & 0.27 & 0.06 & 0.0131 \\
\hline $24: 1 n-9$ & $2 \cdot 24$ & 0.35 & 0.44 & $0 \cdot 13$ & $<0.0001$ \\
\hline Total MUFA & $17 \cdot 10$ & 1.11 & $25 \cdot 22$ & 2.95 & $<0.0001$ \\
\hline $18: 2 n-6$ & $9 \cdot 69$ & 1.33 & $19 \cdot 16$ & $2 \cdot 73$ & $<0.0001$ \\
\hline $18: 3 n-6$ & 0.03 & 0.04 & 0.28 & $0 \cdot 10$ & $<0.0001$ \\
\hline $20: 2 n-6$ & 0.20 & 0.04 & 0.19 & 0.04 & 0.2097 \\
\hline $20: 3 n-6$ & 1.57 & 0.37 & 1.25 & 0.31 & $<0.0001$ \\
\hline $20: 4 n-6$ & $13 \cdot 01$ & 1.61 & $7 \cdot 30$ & 1.50 & $<0.0001$ \\
\hline $22: 4 n-6$ & $2 \cdot 20$ & 0.60 & 0.80 & 0.27 & $<0.0001$ \\
\hline $22: 5 n-6$ & 0.35 & 0.13 & 0.12 & 0.06 & $<0.0001$ \\
\hline Total $n-6$ PUFA & $27 \cdot 05$ & $2 \cdot 61$ & $29 \cdot 12$ & 3.47 & 0.001 \\
\hline $18: 3 n-3$ & 0.15 & 0.04 & 0.50 & 0.22 & $<0.0001$ \\
\hline $20: 5 n-3$ & 1.49 & 0.90 & $1 \cdot 13$ & 0.75 & 0.0305 \\
\hline $22: 5 n-3$ & $2 \cdot 73$ & 0.57 & $1 \cdot 10$ & 0.28 & $<0.0001$ \\
\hline $22: 6 n-3$ & 4.84 & 1.11 & $2 \cdot 18$ & 0.59 & $<0.0001$ \\
\hline Total $n$-3 PUFA & $9 \cdot 21$ & $2 \cdot 08$ & 4.91 & 1.35 & $<0.0001$ \\
\hline 16:0 DMA & $2 \cdot 21$ & 0.21 & 1.03 & 0.17 & $<0.0001$ \\
\hline 18:0 DMA & 3.58 & 0.38 & 1.51 & 0.27 & $<0.0001$ \\
\hline 18:1 DMA & 1.07 & 0.19 & 0.51 & 0.15 & $<0.0001$ \\
\hline Total DMA & $6 \cdot 86$ & 0.47 & 4.91 & 1.35 & $<0.0001$ \\
\hline $20: 4 n-6 / 20: 5 n-3$ & $12 \cdot 21$ & 7.06 & $9 \cdot 25$ & $5 \cdot 34$ & 0.0188 \\
\hline$\%$ n-3 HUFA/total HUFA & 34.65 & 8.06 & 31.74 & $8 \cdot 32$ & 0.0758 \\
\hline$n-6 / n-3$ & $2 \cdot 94$ & 1.26 & 5.93 & 2.57 & $<0.0001$ \\
\hline
\end{tabular}

PL, phospholipids; DMA, dimethyl acetals; HUFA, highly unsaturated fatty acids.

$7 \mathrm{~d}$ and further reductions after 14 and $28 \mathrm{~d}$ storage. The reduction over $28 \mathrm{~d}$ was $8 \%$.

Data obtained from the blood stability trial comparing Whatman sample collection cards pre-treated with BHT or with no added BHT showed that while DHA concentrations reduced steadily from $2.93 \%$ in the initial samples to $1.95 \%$ after 4 weeks at room temperature there were no significant differences, due to BHT addition, between the samples stored for the same time period. This suggested there was no benefit in adding BHT to the sample cards prior to adding the whole blood spot to the collector cards. Other HUFA responded in a similar way to DHA.

A comparison of the erythrocyte PL fatty acid compositions with whole blood fatty acid compositions, collected and analysed from a blood spot applied to a collection device, as described above, is shown in Table 2. Of the thirty-five individual fatty acids, fatty acid groups or ratios measured, all values were significantly different between the erythrocyte PL and whole blood fatty acids with the exception of $20: 2 n-6$ and the percentage $n-3$ HUFA:total HUFA ratio. Whole blood fatty acids showed higher values for the SFA, 14:0, 15:0, $16: 0$ and all MUFA with the exception of $24: 1 n-9$. In the PUFA and HUFA, higher values were seen in the whole blood for the PUFA, $18: 2 n-6,18: 3 n-6$ and $18: 3 n-3$ while all HUFA of both the $n-3$ and $n-6$ series were significantly lower in whole blood samples compared with erythrocyte PL. All the dimethyl acetal fatty acids were significantly lower in whole blood compared with erythrocyte PL as was the case for the ARA:EPA ratio although the $n-6: n-3$ ratio was higher in the whole blood fatty acids.

From the total study population, twenty-seven patients who did not consume any fish oil supplements, were selected, and the comparison of the erythrocyte PL and whole blood fatty acid compositions is shown in Table 3. As was the case for the total study group only two fatty acids out of thirtyfive were not significantly different between the erythrocyte PL and whole blood fatty acids. These included $20: 2 n-6$, which was also the case in the whole study group in Table 3, and the total $n$ - 6 fatty acids, which differed from the whole study group.

Table 3. A comparison of the fatty acid compositions (percentage of total fatty acids) of the erythrocyte polar lipid fraction and whole blood fatty acid compositions in patients who did not consume fish oil supplements

(Mean values and standard deviations, $n$ 27)

\begin{tabular}{|c|c|c|c|c|c|}
\hline \multirow[b]{2}{*}{ Fatty acid } & \multicolumn{2}{|c|}{ Erythrocyte PL } & \multicolumn{2}{|c|}{ Whole blood } & \multirow[b]{2}{*}{$P$} \\
\hline & Mean & SD & Mean & SD & \\
\hline $14: 0$ & 0.29 & 0.07 & 0.96 & 0.42 & $<0.0001$ \\
\hline $15: 0$ & 0.18 & 0.03 & 0.46 & 0.14 & $<0.0001$ \\
\hline $16: 0$ & 20.91 & 1.07 & $23 \cdot 76$ & 1.58 & $<0.0001$ \\
\hline $18: 0$ & $15 \cdot 27$ & 0.81 & $11 \cdot 70$ & 1.07 & $<0.0001$ \\
\hline $20: 0$ & 0.29 & 0.03 & 0.20 & 0.04 & $<0.0001$ \\
\hline $22: 0$ & 0.76 & 0.10 & 0.28 & 0.08 & $<0.0001$ \\
\hline $24: 0$ & 2.02 & 0.26 & 0.32 & 0.11 & $<0.0001$ \\
\hline Total SFA & 39.72 & 0.79 & 37.69 & $1 \cdot 36$ & $<0.0001$ \\
\hline $16: 1 n-9$ & 0.09 & 0.02 & 0.68 & 0.37 & $<0.0001$ \\
\hline $16: 1 n-7$ & 0.31 & 0.10 & 1.47 & 0.47 & $<0.0001$ \\
\hline $18: 1 n-9$ & $12 \cdot 62$ & 0.95 & $20 \cdot 47$ & $2 \cdot 86$ & $<0.0001$ \\
\hline $18: 1 n-7$ & 1.37 & 0.14 & 1.91 & 0.25 & $<0.0001$ \\
\hline $20: 1 n-9$ & 0.22 & 0.05 & 0.26 & 0.06 & 0.0103 \\
\hline $24: 1 n-9$ & $2 \cdot 21$ & 0.30 & 0.45 & 0.14 & $<0.0001$ \\
\hline Total MUFA & $16 \cdot 83$ & 0.95 & $25 \cdot 26$ & $3 \cdot 33$ & $<0.0001$ \\
\hline $18: 2 n-6$ & 9.95 & $1 \cdot 12$ & $19 \cdot 16$ & $2 \cdot 30$ & $<0.0001$ \\
\hline $18: 3 n-6$ & 0.03 & 0.04 & 0.28 & 0.09 & $<0.0001$ \\
\hline $20: 2 n-6$ & 0.20 & 0.04 & 0.19 & 0.04 & 0.3626 \\
\hline $20: 3 n-6$ & 1.63 & 0.33 & $1 \cdot 31$ & 0.30 & 0.0005 \\
\hline $20: 4 n-6$ & $13 \cdot 88$ & $1 \cdot 11$ & $7 \cdot 84$ & 1.53 & $<0.0001$ \\
\hline $22: 4 n-6$ & 2.53 & 0.44 & 0.94 & 0.21 & $<0.0001$ \\
\hline $22: 5 n-6$ & 0.41 & 0.11 & 0.16 & 0.05 & $<0.0001$ \\
\hline Total $n-6$ PUFA & 28.63 & 1.57 & $29 \cdot 88$ & 3.50 & 0.0964 \\
\hline $18: 3 n-3$ & 0.16 & 0.05 & 0.50 & 0.18 & $<0.0001$ \\
\hline $20: 5 n-3$ & 0.91 & 0.26 & 0.67 & 0.19 & 0.0003 \\
\hline $22: 5 n-3$ & 2.47 & 0.29 & 1.02 & 0.18 & $<0.0001$ \\
\hline $22: 6 n-3$ & $4 \cdot 38$ & 1.05 & 1.98 & 0.59 & $<0.0001$ \\
\hline Total $n-3$ PUFA & 7.92 & $1 \cdot 27$ & $4 \cdot 16$ & 0.82 & $<0.0001$ \\
\hline $16: 0$ DMA & $2 \cdot 24$ & 0.19 & 1.01 & 0.14 & $<0.0001$ \\
\hline 18:0 DMA & 3.66 & 0.40 & 1.52 & 0.25 & $<0.0001$ \\
\hline 18: 1 DMA & 1.01 & 0.11 & 0.47 & 0.10 & $<0.0001$ \\
\hline Total DMA & 6.91 & 0.49 & 3.01 & 0.45 & $<0.0001$ \\
\hline $20: 4 n-6 / 20: 5 n-3$ & $16 \cdot 74$ & $6 \cdot 07$ & $12 \cdot 65$ & 4.51 & 0.007 \\
\hline$\% n-3$ HUFA/total HUFA & 29.63 & $4 \cdot 74$ & $26 \cdot 43$ & $4 \cdot 19$ & 0.0113 \\
\hline$n-6 / n-3$ & 3.74 & 0.79 & $7 \cdot 42$ & 1.55 & $<0.0001$ \\
\hline
\end{tabular}

PL, phospholipids; DMA, dimethyl acetals; HUFA, highly unsaturated fatty acids. 
Table 4. Precision of the new whole blood method when analysing the same sample in triplicate over $4 \mathrm{~d}$

(Mean values and standard deviations, coefficient of variation (\%) and ranges, $n$ 12)

\begin{tabular}{|c|c|c|c|c|}
\hline Fatty acid & Mean & SD & $\mathrm{CV} \%$ & Range \\
\hline $16: 0$ & 24.35 & 0.34 & 1.40 & $23.87-25.01$ \\
\hline $18: 0$ & $10 \cdot 79$ & 0.11 & 1.01 & $10.60-10.94$ \\
\hline Total SFA & 37.06 & 0.41 & $1 \cdot 10$ & $36 \cdot 48-37 \cdot 84$ \\
\hline $18: 1 n-9$ & $20 \cdot 18$ & 0.19 & 0.94 & $19 \cdot 90-20 \cdot 44$ \\
\hline Total MUFA & 24.98 & 0.23 & 0.92 & $24.45-25 \cdot 31$ \\
\hline $18: 2 n-6$ & 21.53 & 0.14 & 0.65 & $21 \cdot 32-21 \cdot 80$ \\
\hline $20: 4 n-6$ & $6 \cdot 32$ & 0.13 & 2.06 & $6 \cdot 13-6 \cdot 53$ \\
\hline Total $n-6$ & 30.44 & 0.20 & 0.66 & $30 \cdot 15-30 \cdot 83$ \\
\hline $20: 5 n-3$ & 0.84 & 0.02 & $2 \cdot 38$ & $0.82-0.88$ \\
\hline $22: 6 n-3$ & 1.84 & 0.02 & 1.09 & $1.81-1.88$ \\
\hline Total $n-3$ & $4 \cdot 17$ & 0.10 & 2.40 & $4.02-4.35$ \\
\hline ARA/EPA & 7.41 & 0.18 & 2.43 & $7 \cdot 23-7 \cdot 86$ \\
\hline$\% n-3$ HUFA/total HUFA & 29.97 & 0.37 & 1.24 & $29.07-30.52$ \\
\hline
\end{tabular}

HUFA, highly unsaturated fatty acids.

To assess the precision of the whole blood analysis method a single whole blood sample was analysed, in triplicate, over four consecutive days. The results for seven major whole blood fatty acids, total saturates, monounsaturates, total $n-6$ and $n-3$ fatty acids as well as the ARA:EPA ratio and the percentage $n$-3HUFA:total HUFA ratio are shown in Table 4. The results obtained show that the method precision for the major fatty acids, groups and ratios gave $\mathrm{CV} \%$ values that were acceptable for all the fatty acids measured and were similar to those reported in the literature ${ }^{(12)}$.

Graphs showing the correlations between ARA, EPA, DHA, ARA:EPA ratio and the percentage $n$ - 3 HUFA:total HUFA, comparing fatty acid values from erythrocyte PL with corresponding values from whole blood spot data, are shown in Figs. $1-5$. The correlations were generally good although the $r^{2}$ values for ARA and DHA were the lowest at 0.48 and 0.59 , respectively, although there were much stronger correlations for EPA $\left(r^{2} 0.89\right)$, ARA:EPA ratio $\left(r^{2} 0.94\right)$ and the percentage $n-3$ HUFA:total HUFA $\left(r^{2} 0.95\right)$.

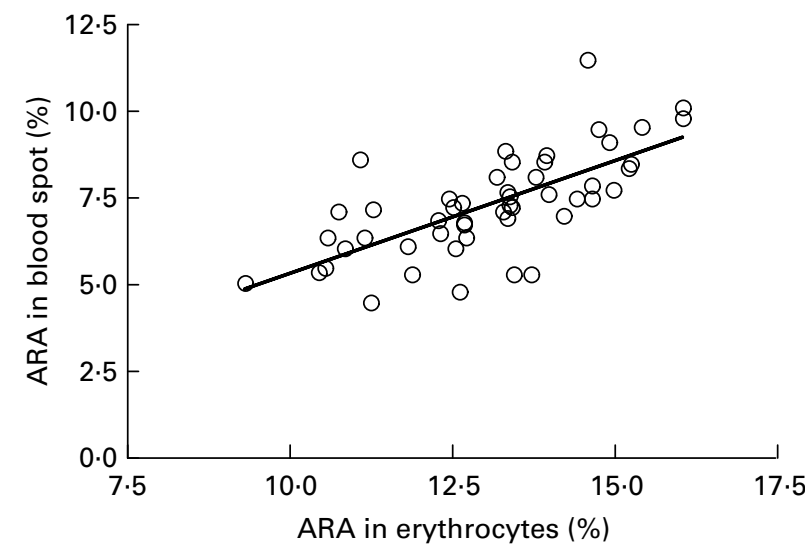

Fig. 1. Correlation between arachidonic acid (ARA) (percentage of total fatty acids; TFA) in erythrocyte polar lipid fraction (erythrocytes), collected by venepuncture, compared with the ARA (\% TFA) in whole blood spot collected by finger prick from fifty-one patients. $r^{2} 0.483$.

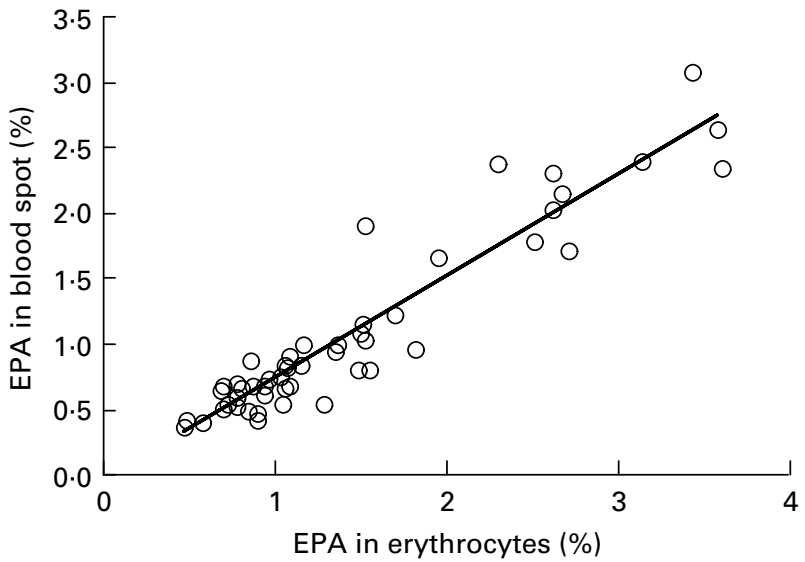

Fig. 2. Correlation between EPA (percentage of total fatty acids; TFA) in erythrocyte polar lipid fraction (erythrocytes), collected by venepuncture, compared with the EPA (\% TFA) in whole blood spot collected by finger prick from fifty-one patients. $r^{2} 0 \cdot 887$.

\section{Discussion}

There is now conclusive evidence that increasing the intake of $n$-3 HUFA, in particular EPA and DHA, can prevent or attenuate CVD as well as other conditions with an inflammatory pathology, including type 2 diabetes, rheumatoid arthritis, asthma and some forms of cancer ${ }^{(3,19,20)}$. There is also evidence of benefit in consuming $n-3$ HUFA for retinal function and for a range of neurological and neurodegenerative disorders $^{(6,21)}$. Thus, the increasing interest in $n-3$ HUFA as a medical intervention for a range of conditions has simultaneously increased demand for the development of more rapid, accurate and cost-effective methods of blood analysis.

However, clinical studies have used a number of different blood fractions when measuring fatty acid compositions including erythrocyte TL and PL, plasma TL and PL, plasma TAG and platelet TL and among others ${ }^{(22-24)}$. Among these different fractions, measurement of the erythrocyte PL fraction has been regarded by many investigators as the 'gold standard' that might estimate, long-term dietary HUFA intake influenced

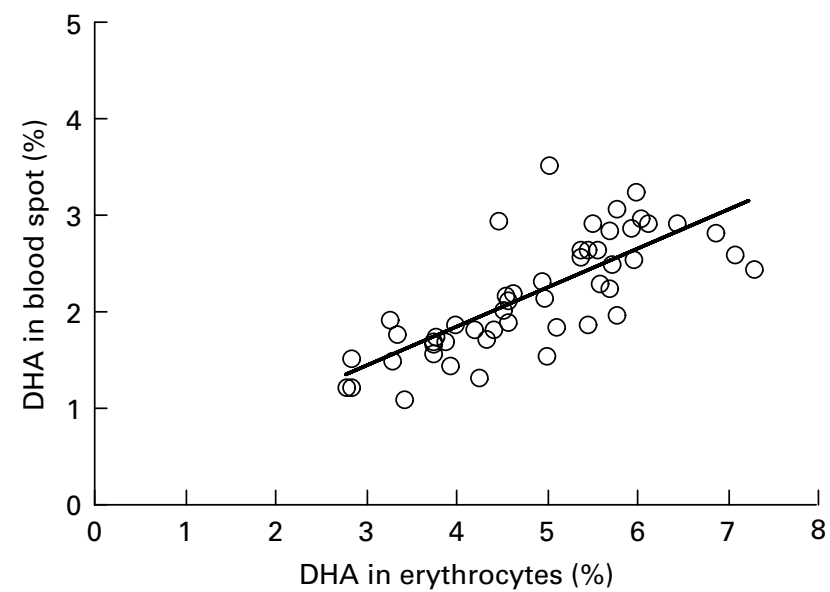

Fig. 3. Correlation between DHA (percentage of total fatty acids; TFA) in erythrocyte polar lipid fraction (erythrocytes), collected by venepuncture, compared with the DHA (\% TFA) in whole blood spot collected by finger prick from fifty-one patients. $r^{2} 0.579$. 


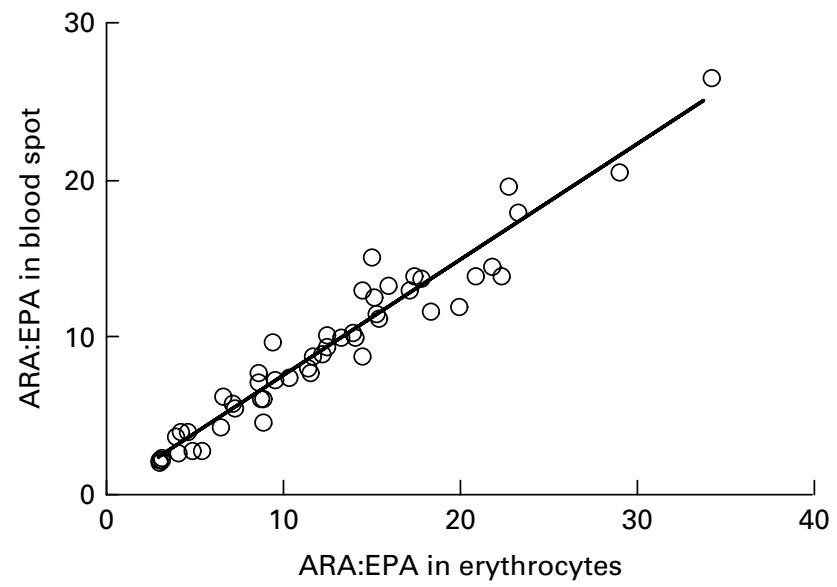

Fig. 4. Correlation between the ARA/EPA ratio in erythrocyte polar lipid fraction (erythrocytes), collected by venepuncture, compared with the ARA/EPA ratio in whole blood spot collected by finger prick from fifty-one patients. $r^{2} 0.937$.

by the erythrocyte lifespan of approximately $125 \mathrm{~d}^{(25,26)}$. However, the observed similar proportions of $n-3$ in HUFA of plasma and erythrocytes may be reconciled when longstanding awareness of continual remodelling of acids in erythrocyte membrane phospholipids $(\mathrm{PL})^{(27)}$ is included in the consideration. In addition, extraction, methylation, purification and chromatography involved in this intensive analytical procedure do not allow the high sample throughput required when analysing large sample numbers from clinical trials. In addition, the collection of venous blood from some patients, particularly young infants and the elderly, can prove difficult and can raise ethical concerns.

In the present study, we have developed a rapid, accurate and inexpensive method that is minimally invasive and involves the collection of a drop of whole blood, using a disposable blood lance, which can be stored on absorbent paper, and subjected to direct methylation techniques and allows a high sample throughput providing compositional data within $1-2 \mathrm{~d}$. For most fatty acids significant differences were observed when comparing erythrocyte PL with whole blood lipids and this is due to the contribution of several lipid classes including TAG, PL, steryl esters and NEFA in the latter compared to the largely PL input in the former. The SFA, 14:0 and 15:0, were relatively higher in the whole blood than in the erythrocyte PL as these are not found in PL to any great degree. However, the saturates that have a structural role in the PL, particularly 18:0 and 24:0, were higher in the erythrocyte PL while 16:0, which also has a structural role in PL, as well as being abundant in neutral lipids, was similar in both PL and whole blood. In the MUFA all were higher in whole blood than in erythrocyte PL, which reflects their abundance in neutral lipids, with the exception of $24: 1$, which has important structural roles in $\mathrm{PL}$ and sphingolipids. In the $\mathrm{C}_{18}$ PUFA higher values were recorded in the whole blood than in erythrocyte PL as these fatty acids are mainly found in the neutral lipids with lower concentrations located in the PL fraction. By comparison, the HUFA, namely $20: 3 n-6$, ARA, $22: 4 n-6$ and $22: 5 n-6$ of the $n$ - 6 series and EPA, $22: 5 n$ - 3 and DHA of the $n$ - 3 series were more abundant in the erythrocyte PL reflecting their structural importance relating to cell membrane function. This was particularly noticeable for ARA and DHA where the values in whole blood in the fifty-one patients represented 56 and $45 \%$ of the values in erythrocyte PL, respectively. The abundance of ARA and DHA in membrane PL reflects not only their importance to erythrocyte function but also their roles in all cellular membranes, but especially so in neural tissues $^{(7,20,28)}$. An earlier study compared the HUFA compositions in erythrocyte PL and whole blood samples collected by finger prick ${ }^{(15)}$. The percentage values recorded for ARA in erythrocytes $v$. whole blood were $10 \cdot 6 / 8 \cdot 06$, which is similar to the values of $13 \cdot 0 / 7 \cdot 3$ observed in the present study. The values for DHA were in fact closer, being $4 \cdot 36 / 2 \cdot 76$ and $4 \cdot 84 / 2 \cdot 18$, respectively for the study by Bailey-Hall et al. ${ }^{(15)}$, and the present study, respectively.

The storage stability trial analysed samples at regular intervals from $3 \mathrm{~h}$ to 1 month following storage at either 4 or $-20^{\circ} \mathrm{C}$. For ARA, EPA and DHA at $4^{\circ} \mathrm{C}$, progressive reductions were seen from $48 \mathrm{~h}$ onwards with reductions of 15, 29 and $25 \%$ observed after 1 month (Table 2). For the ARA:EPA ratio values increased over time due to EPA declining more quickly than ARA such that values at 1 month were $16 \%$ higher than at the start. The percentage $n-3$ HUFA/total HUFA values were the most stable being reduced by only $8 \%$ after storage for 1 month at $4^{\circ} \mathrm{C}$. For samples stored at $-20^{\circ} \mathrm{C}$ for 1 month reduction in HUFA and ratios were much lower (Table 2). No reduction over time was seen for ARA while there was no loss of EPA or DHA until $14 \mathrm{~d}$ in storage and losses were 9.1 and $4.7 \%$ after 1 month, respectively. As above the ARA:EPA ratio after 1 month at $-20^{\circ} \mathrm{C}$ was reduced by $9 \%$ while the percentage $n-3$ HUFA/total HUFA values were reduced after $14 \mathrm{~d}$ but only by $3 \%$ over the month.

In the present study, we compared the correlations between erythrocyte PL fatty acids and whole blood finger-prick assays in the fifty-one patients for ARA, EPA, DHA, ARA:EPA ratio

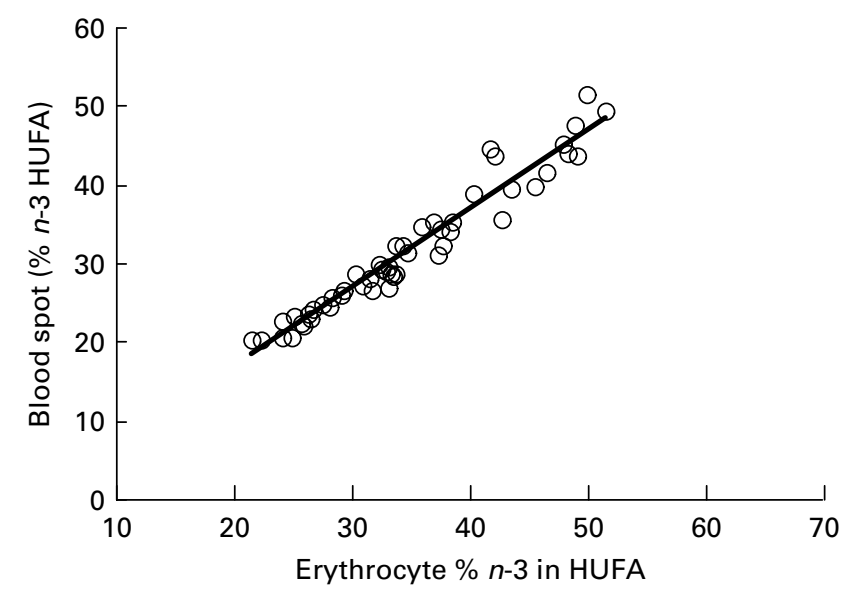

Fig. 5. Correlation between the percentage $n-3$ highly unsaturated fatty acid (HUFA)/total HUFA in erythrocyte polar lipid fraction (erythrocytes), collected by venepuncture, compared with the percentage $n-3$ HUFA/total HUFA in whole blood spot collected by finger prick from fifty-one patients. $n-3$ HUFA $=\mathrm{EPA}+22: 5 n-3+\mathrm{DHA}$ and $n-6$ HUFA $=20: 3 n-6+\mathrm{ARA}+22:$ $4 n-6+22: 5 n-6 . r^{2} 0.946$. 
and percentage $n-3$ HUFA/total HUFA. The poorest correlation was seen for ARA, which had an $r^{2}$ value of 0.48 in the present study, which was similar to the value of 0.41 recorded by Bailey-Hall et $a l^{(15)}$. An earlier study by Ichihara et $a l^{(29)}$ suggested that the correlation of ARA could be improved if it was expressed as a ratio such as ARA:(EPA + DHA) and, as such was an indicator of $n-6: n-3$ status. Using this ratio increased the $r^{2}$ value to 0.93 , for whole blood $v$. erythrocyte $\mathrm{PL}^{(15)}$ while in the present study the ARA:EPA ratio had an almost identical $r^{2}$ value of 0.94 although in the study by Rizzo et al. ${ }^{(16)}$ a slightly lower value of 0.87 was recorded. For EPA the correlation between erythrocyte PL and whole blood gave an $r^{2}$ value of 0.89 , which is considerably higher than the value of 0.64 recorded by Bailey-Hall et al. ${ }^{(15)}$. This difference might relate to the wider ranges obtained in the present study compared with the Bailey-Hall et al. ${ }^{(15)}$ study $(0.4-3.6 v \cdot 0 \cdot 2-2 \cdot 4$ in erythrocyte $\mathrm{PL})$ and $(0 \cdot 4-3.0 v$. $0 \cdot 18-1.6$ in the whole blood). Conversely, for DHA the opposite effect was seen when comparing the present trial with that of Bailey-Hall et al. ${ }^{(15)}$ with the $r^{2}$ values being 0.58 and 0.86 , respectively. As with EPA, this might be explained by the wider ranges seen in the Bailey-Hall et al. ${ }^{(15)}$ study compared with the present study $(1 \cdot 7-7 \cdot 0 \mathrm{v} \cdot 2 \cdot 8-7 \cdot 2$ in erythrocyte PL) and $(1 \cdot 1-4 \cdot 3 v \cdot 1 \cdot 1-3 \cdot 5)$.

The percentage $n$ - 3 HUFA:total HUFA ratio that includes EPA, DPA and DHA of the $n-3$ series and 20:3n-6, ARA, $22: 4 n-6$ and $22: 5 n-6$ gave the best correlation between whole blood and erythrocyte PL in the present study with an $r^{2}$ value of 0.95 . This value is very similar to that reported by Stark $^{(9)}$, of 0.93 and 0.94 for plasma and erythrocytes, respectively. The use of percentage $n-3$ HUFA/total HUFA was also shown to provide the most consistent estimates of $n-3$ fatty acid status with stronger correlations across different blood matrices when compared with only considering sum $\mathrm{EPA}+\mathrm{DHA}^{(10,13,30)}$. It is noteworthy that comparing the percentage $n-3$ HUFA/total HUFA between the present study in Scotland, with those by Marangoni et al. ${ }^{(13)}$ (Italy) and Stark $^{(9)}$ (USA) show values of 26.43 in Scotland, 25.76 in Italy and $20 \cdot 17$ in the USA. These values are all relatively low and reflect the low fish intake in most Western $\operatorname{diets}^{(16,31)}$. The equations developed by Lands et al. ${ }^{(32)}$ suggested that adding $750 \mathrm{mg}$ of EPA + DHA to the typical North American diet, without changing other fatty acid intake, would provide significant cardioprotection and would increase the ratio to $44 \%$. A value of $40 \%$ has been predicted to reduce mortality from myocardial infarction and this approximates to an EPA + DHA value of $8 \%$ of total erythrocyte fatty acids ${ }^{(33,34)}$.

In conclusion, the increasing interest in the use of $n-3$ HUFA as beneficial interventions in a range of inflammatory disorders prevalent in Western populations requires the development of methods to assess efficacy of the intervention. The collection of whole blood that can be immobilised and stored on absorbent paper and directly derivatised to allow a cheap, rapid and reproducible analysis of fatty acid compositions in large cohorts is a valuable addition in the evaluation of disease risk and subsequent treatment. The use of the percentage $n$ - 3 HUFA:total HUFA ratio appears to be a robust measure of HUFA status across a range of blood fractions and HUFA concentrations. The evidence from the present study suggests that this methodology has the potential to relate blood HUFA with dietary intake and physiological biomarkers that could assist in fine-tuning therapeutic interventions. The present study demonstrates that individual HUFA, and their relative proportions, can be measured accurately from a whole blood spot. This provides an economical and rapid alternative to current labour-intensive methods that require centrifugation and complex analysis of erythrocyte lipid classes. The method described here eliminates the cost and time to isolate erythrocytes and offers researchers, clinicians and the public an alternative method that should become less costly as increased use provides economy of scale. The results obtained demonstrate the validity of simplified analytical methods that make them both easily available and understandable to clinicians and public user groups. The rapid blood test is currently marketed as the Ideal Omega Test ${ }^{\mathrm{TM}}$ (GHS Ltd, Poulton Le Fylde, Lancashire, UK). To assess this methodology fully will require further largescale trials that should incorporate rapid methods of automated sample processing coupled with fast GC technology in an effort to reduce analysis times.

\section{Acknowledgements}

The present study was funded by Scottish Enterprise. J. G. B. wrote the manuscript with assistance from all other authors in particular J. R. D., T. G. and B. L.; T. G. was responsible for sample collection and J. R. D., E. E. M. and I. Y. were responsible for sample processing, GC analysis and data processing. All authors read and approved the findings of the study. T. G. is Clinical Director of Glasgow Health Solutions Limited. None of the other authors had a conflict of interest.

\section{References}

1. Ruxton CHS, Calder PC, Reed SC, et al. (2005) The impact of long-chain $n$-3 polyunsaturated fatty acids on human health. Nutr Res Rev 18, 113-129.

2. Calder PC (2010) The 2008 ESPEN Sir David Cuthbertson lecture: fatty acids and inflammation - from the membrane to the nucleus and from the laboratory bench to the clinic. Clin Nutr 29, 5-12.

3. Maclean CH, Mojica WA, Morton SC, et al. (2004) Effects of omega-3 fatty acids on lipids and glycemic control in type II diabetes and the metabolic syndrome and on inflammatory bowel disease, rheumatoid arthritis, renal disease, systemic lupus erythromatosus, and osteoporosis. Evid Rep Technol Assess (Summ) 89, 1-4.

4. Bjøkkaer T, Brun JG, Valen M, et al. (2006) Short-term duodenal seal oil administration normalised $n-6$ to $n-3$ fatty acid ratio in rectal mucosa and ameliorated bodily pain in patients with inflammatory bowel disease. Lipids Health Dis 5, 6.

5. Dyerberg J, Bang HO \& Hjorne N (1975) Fatty acid composition of the plasma lipids in Greenland Eskimos. Am J Clin Nutr 28, 958-966.

6. Young G \& Conquer J (2005) Omega-3 fatty acids and neuropsychiatric disorders. Reprod Nutr Dev 45, 1-28. 
7. Hibbeln JR, Nieminen LR, Blasbalg TL, et al. (2006) Healthy intakes of $n-3$ and $n-6$ fatty acids: estimations considering worldwide diversity. Am J Clin Nutr 83, 1483S-1493S.

8. Hibbeln JR, Davis JM, Steer C, et al. (2007) Maternal seafood consumption in pregnancy and neurodevelopmental outcomes in childhood (ALSPAC study): an observational cohort study. Lancet 369, 578-585.

9. Stark KD (2008) The percentage of $n-3$ highly unsaturated fatty acids in total HUFA as a biomarker for omega- 3 fatty acid status in tissues. Lipids $\mathbf{4 3}$, 45-53.

10. Metherel AH, Armstrong JM, Patterson AC, et al. (2009) Assessment of blood measures of the $n-3$ polyunsaturated fatty acids with acute fish oil supplementation and washout in men and women. Prostaglandins Leukot Essent Fatty Acids 81, 23-29.

11. Lands WEM, Hamazaki T, Yamazaki K, et al. (1990) Changing dietary patterns. Am J Clin Nutr 51, 991-993.

12. Maragoni F, Colombo C \& Galli C (2004) A method for the direct evaluation of the fatty acid status in a drop of blood from a fingertip in humans: applicability to nutritional and epidemiological studies. Anal Biochem 326, 267-272.

13. Marangoni F, Colombo C, Martiello A, et al. (2007) The fatty acid profiles in a drop of blood from a fingertip correlate with physiological, dietary and lifestyle parameters in volunteers. Prostaglandins Leukot Essent Fatty Acids 76, 87-92.

14. Armstrong JM, Metherel AH \& Stark KD (2008) Direct microwave transesterification of fingertip prick blood samples for fatty acid determinations. Lipids $\mathbf{4 3}$, 187-196.

15. Bailey-Hall E, Nelson EB \& Ryan AS (2008) Validation of a rapid measure of blood PUFA levels in humans. Lipids $\mathbf{4 3}$, 181-186.

16. Rizzo AM, Montorfano G, Negroni M, et al. (2010) A rapid method for determining arachidonic:eicosapentaenoic acid ratios in whole blood lipids: correlation with erythrocyte membrane ratios and validation in a large population of various ages and pathologies. Lipids Health Dis 9, 7.

17. Bligh EG \& Dyer WJ (1959) A rapid method of total lipid extraction and purification. Can J Biochem Physiol 37, 911-917.

18. Christie WW (2003) Lipid Analysis, 3rd ed., pp. 205-224. Bridgewater: The Oily Press.

19. Siddiqui RA, Hravey KA, Ruzmetov N, et al. (2009) n-3 fatty acids prevent whereas trans-fatty acids induce vascular inflammation and sudden cardiac death. Br J Nutr 102, 1811-1819.

20. Schachter HM, Kourad K, Merali Z, et al. (2005) Effects of omega-3 fatty acids on mental health. Evid Rep Technol Assess (Summ) 89, 1-11.

21. Hodge W, Barnes D, Schachter HM, et al. (2005) Effects of omega-3 fatty acids on eye health. Evid Rep Technol Assess (Summ) 117, 1-6.

22. Marangoni F, Angeli MT, Colli S, et al. (1993) Changes of $n-3$, $n-6$ fatty acids in plasma and circulating cells of normal subjects after prolonged administration of 20:5 (EPA) and 22:6 (DHA) ethyl esters and prolonged washout. Biochim Biophys Acta 1210, 55-62.

23. Bell JG, Miller D, MacDonald DJ, et al. (2010) The fatty acid compositions of red blood cell and plasma polar lipids in children with autism, developmental delay or typically developing controls and the effect of fish oil intake. $\mathrm{BrJ}$ Nutr 103, 1160-1167.

24. Katan MB, Deslypere JP, van Birgelen AP, et al. (1997) Kinetics of the incorporation of dietary fatty acids into serum cholesteryl esters, erythrocyte membranes, and adipose tissue: an 18 month controlled study. J Lipid Res $\mathbf{3 8}$, 2012-2022.

25. Harris WS \& von Schacky C (2004) The omega-3 index: a new risk factor for death from coronary heart disease? Prev Med 39, 212-220.

26. Poppitt SD, Kilmartin P, Butler P, et al. (2005) Assessment of erythrocyte phospholipid fatty acid composition as a biomarker for dietary MUFA, PUFA or saturated fatty acid intake in a controlled crossover intervention trial. Lipids Health Dis 5, 30.

27. Waku K \& Lands WEM (1968) Control of lecithin biosynthesis in erythrocyte membranes. J Lipid Res 9, 12-18.

28. Maclean CH, Issa AM, Newberry SJ, et al. (2005) Effects of omega-3 fatty acids on cognitive function with aging, dementia, and neurological diseases. Evid Rep Technol Assess (Summ) 114, 1-3.

29. Ichihara A, Waku K, Yamaguchi C, et al. (2002) A convenient method for determination of the $\mathrm{C}_{20-22}$ PUFA composition of the glycerolipids in blood and breast milk. Lipids 37, 523-526.

30. Lands B (2009) Measuring blood fatty acids as a surrogate indicator for coronary heart disease risk in population studies. In $A$ Balanced Omega-6/Omega-3 Fatty Acid Ratio, Cholesterol and Coronary Heart Disease, pp. 22-34 [AP Simopoulo and F De Meester, editors]. World Rev Nutr Diet Karger, Basel.

31. Innis SM \& Elias SL (2003) Intakes of essential $n-6$ and n-3 polyunsaturated fatty acids among pregnant Canadian women. Am J Clin Nutr 77, 473-478.

32. Lands WE, Libelt B, Morris A, et al. (1992) Maintenance of lower proportions of $(n-6)$ eicosanoid precursors in phospholipids of human plasma in response to added dietary (n-3) fatty acids. Biochim Biophys Acta 1180, 147-162.

33. Dolecek TA (1992) Epidemiological evidence of relationships between dietary polyunsaturated fatty acids, and mortality in the multiple risk factor intervention trial. Proc Soc Exp Biol Med 200, 177-182.

34. Lands WE (2005) Dietary fat and health: the evidence and the politics of prevention: careful use of dietary fats can improve life and prevent disease. Ann NY Acad Sci 1055, $177-182$. 